since the response was independent of the level of available nitrogen supply.

S. Andersen (Denmark) and Prof. B. Rademacher (Germany) gave accounts of experiments which sought to correlate weather conditions with the effects of substituted phenoxyacetic acids on cereals. J. D. Fryer and J. G. Elliott (Oxford) and T. C. Breese (Plant Protection, Ltd.) were in general agreement that, while wheat and barley cannot safely be sprayed until the plants reach the five-leaf stage, the optimum time to spray oats with 2-methyl4-chlorophenoxyacetic acid is in the one- to four-leaf stage. For perennial grasses the importance of the stage of development in relation to the timing of spray applications was illustrated in the contribution of R. S. L. Jeater (National Institute of Agricultural Botany), who described the complex inter-relationships between species, time of application and the abnormalities induced in the flower primordia and inflorescences.

Three papers were devoted to the means of controlling Agropyron repens; in Great Britain the emphasis has been on sodium trichloroacetate, while in Sweden, so Prof. H. Osvald and Dr. E. Aberg reported, comparisons are being made of sodium chlorate, sodium trichloroacetate and 2,2-dichloropropionic acid. Dr. H. P. Allen. (Plant Protection, Ltd.) described trials carried out in Malaya with phenyl-substituted ureas for the eradication of lalang (Imperata cylindrica). Neither 3(3,4-dichlorophenyl)1,1-dimethyl urea nor 3( $p$-chlorophenyl)-1,1-dimethylurea resulted in complete control of this species unless the rates of application excerded $80 \mathrm{lb}$. per acre. On the whole, better results were achieved when the treatment consisted of sodium trichloroacetate at 150-200 lb. per acre.

Prof. G. E. Blackman (Oxford) outlined the programme of investigations being conducted in East Africa by Dr. G. W. Ivens (Colonial Insecticide Research Unit, Tanganyika) in conjunction with the Agricultural Research Council's Unit at Oxford. The main object is to determine how far defoliants and arboricides can be used as means of eliminating tsetse flies through vegetation control. Experiments have shown that aircraft applications of the $n$-butyl ester of 2,4,5-trichlorophenoxyacetic acid are capable of defoliating, or even killing, a range of trees and shrubs found in communities which provide habitats for important species of tsetse fly. Besides applications from aircraft, other uses for such materials are being studied, and there is some evidence from Uganda that in high forest species of valueless trees can be eliminated by spraying the base of the tree with a suitable formulation of an arboricide, such as 2,4,5-trichlorophenoxyacetic acid.

\section{FEDERATION OF MATHEMATICS AND PHYSICS SOCIETIES OF YUGOSLAVIA \\ CONGRESS IN ZAGREB}

T

THE second congress of the Federation of Mathematics and Physics Societies of Yugoslavia was held in Zagreb during October 4-9, more than six hundred delegates attending. The congress considered a wide range of subjects - in the unanimous opinion of all present, too wide a rango-indicating, among other matter, the growth of mathematics and physics in Yugoslavia. Some of the questions the congress examined were the teaching of mathematics and physies in secondary schools; the teaching at universities ; and the organization of research in mathematics and physics. Eight sessions were devoted to research papers on mathematies, and nine to papers from the field of physics.

The present writer, being concerned mostly with nuclear physics, can give only a sample subject survey of papers in that field. One should bear in mind that this is the first time in the history of Yugoslavia that research papers in physics were reported at a nation-wide reunion of physicists. Altogether, a hundred and five research papers in physics were given, fifty-seven in the field of particle and nuclear physics, and forty-eight in optics, structure of crystals, geophysics, mathematical equipment, etc. A brief mention of the subjects of some of the papers in the field of nuclear and particle physics will indicate the range of interest. Theoretical research papers included one on the derivation of the nuclear forces from quantum field theory, one on the selection rules in meson theory and another two with Coulomb excitation of nuclei. Two communications dealt with the measurement of cosmic rays underground. A series of papers was on nuclear spectroscopy: beta decay of carbon-14, decay schemes of cæsium-133, crsium-134, tungsten185, etc. Other topics considered were the angular distribution in beryllium-9 reactions with deuterons, Auger spectrum of thorium B, the positive particles purported to be accompanying the bota decay of phosphorus-32, the duration of fission, etc. A number of papers dealt with neutron sources, neutron diffusion and calculations of distributions of neutron fluxes. The Stefan Institute of Ljubljana reported on the construction of a mass spectrograph, the Boshkovich Institute of Zagreb on the design of a cyclotron in the range of $20 \mathrm{MeV}$., and the Kidrich Institute of Belgrade on the functioning and improvement of the ion beam of a Cockcroft-Walton accelerator of $1.5 \mathrm{MeV}$.

At the final plenary session the congress adopted a series of decisions to be brought to the attention of the Yugoslav Government and the general public. Those pertaining to physics stressed the necessity of developing research in physics at the universities and urged greater material support of the Physics Department of the University of Belgrade. A systematic study was recommended for the development of physies in the eountry in the light of the development of its economy and the development of physics abroad. Especially underlined was the necessity for a more balanced development of physics research, with support for other branches of research in physics at least equal to that given to nuclear studies. There was considerable discussion, though no formal decision was talven, on the question of starting a central Yugoslav review of physics. At the congress an opinion was expressed that since physics in Yugoslavia is in the process of standing on its own feot, there should be, from an organization point of view, greater autonomy and independence of physics and mathematics activities in Yugoslavia. This point of view was reflected in the election of officers for the executive committee of the Federation, when Prof. G. Kurepa, a mathematician from Zagreb, was elected president, and Mr. A. Milojevich, a physicist, from Belgrade, as secretary for physics.
Stevan DediJer 